\title{
A Study on the Application of Coordinated TOPSIS in Evaluation of Robotics Academic Journals
}

\author{
Liping Yu, ${ }^{1}$ Wenhua Yang, ${ }^{2}$ Yunlong Duan $\mathbb{D}^{2},{ }^{2}$ and Xinwen Long ${ }^{3}$ \\ ${ }^{1}$ School of Management and E-Business, Zhejiang Gongshang University, Hangzhou 310018, China \\ ${ }^{2}$ International Business School, Yunnan University of Finance and Economics, Kunming 650221, China \\ ${ }^{3}$ Library, Southeast University, Nanjing 211189, China \\ Correspondence should be addressed to Yunlong Duan; duanyl1977@126.com
}

Received 26 April 2018; Accepted 28 June 2018; Published 11 July 2018

Academic Editor: Carlos Llopis-Albert

Copyright (C) 2018 Liping Yu et al. This is an open access article distributed under the Creative Commons Attribution License, which permits unrestricted use, distribution, and reproduction in any medium, provided the original work is properly cited.

\begin{abstract}
While TOPSIS is a widely used evaluation method, it lacks evaluation from the perspective of indicator coordination. Based on the analysis of TOPSIS evaluation methods, this paper proposes a new assessment method, coordinated TOPSIS, which takes into account the advantages of TOPSIS evaluation methods and the coordination level of evaluation indicators. Taking the robotics academic journals as an example, the TOPSIS evaluation and the coordinated TOPSIS evaluation results are compared. The research shows that the weights of the coordinated TOPSIS method can be manually adjusted according to the purpose of evaluation and have a good flexibility; the TOPSIS evaluation results and coordinated TOPSIS evaluation results have a high degree of correlation, but the difference from the perspective of the ranking is big; the coordinated TOPSIS is very suitable for evaluation field that needs to consider the coordinated development, and it can be replicated.
\end{abstract}

\section{Introduction}

It is of great significance to evaluate academic journals of robotics. With the rapid development of artificial intelligence, the development of robotics disciplines is very fast. In recent years, robotic academic journals have become increasingly influential, and their influence factors are getting higher and higher, which makes it very important to promote the development of robotics disciplines. The evaluation of robotic academic journals not only helps the competition between different journals and improves the academic quality, but also facilitates the selection of appropriate journals by the author when posting. It provides great value to journals and scholars and they can jointly support the development of robotics disciplines.

TOPSIS is a widely used evaluation method. Since Huang proposed the TOPSIS evaluation method [1], it has been widely applied in an extensive range of fields such as economy, society, and natural sciences. It evaluates the relative distance between the evaluation object and the ideal solution and negative ideal solution. On March 17, 2018, based on Scopus database, a total of 5,630 papers were searched by title, abstract and keyword "TOPSIS". Based on the Ei/Compendex database, a total of 4,144 papers were retrieved when "TOPSIS" was searched in "all fields". Based on the Web of Science database, a total of 2823 papers were found using the search topic "TOPSIS".

In the evaluation of science and technology, TOPSIS has also been widely used. $\mathrm{Xu}$ et al. use the TOPSIS method to evaluate the output of scientific research institutions [2]. Yu et al. use TOPSIS to evaluate academic journals based on panel data [3]. Li et al. adopt fuzzy TOPSIS in multicriteria group decision-making in the study of research institutions output [4]. Yu and Pan study the characteristics and differentiation of TOPSIS under high power and applied it to academic journal evaluation [5].

Just as any evaluation method has its own advantages and disadvantages; TOPSIS also has some room for optimization. Jahanshahloo et al. study the distance calculation formula of the TOPSIS method when the attribute data is a fuzzy number [6] and proposed an improved method. Yu, Pan, et al. put forward a modified TOPSIS method based on the reverse order problem as the points of evaluation value on the vertical line of the line segment between ideal solution 
and negative ideal solutions move [7]. Li and Zhang's study suggests that when the TOPSIS evaluation is conducted [8], if the negative ideal solution of the newly added evaluation object is lower, the problem of disordered sorting will occur, and they recommend some ideas for improvement. Lu and Tang believe that the TOPSIS method has problems in the determination of positive and negative ideal points [9], the determination of weights, and the calculation of closeness, which all lead to disordered sorting. It is proposed to use absolute positive and negative ideal points, and use projection methods to improve the closeness formula. Li, Zhang et al. employ gray correlation closeness to evaluate instead of TOPSIS positive and negative ideal solution distance [10].

Sun et al. evaluate the impact of green technology innovation on ecological-economic efficiency of strategic emerging industries with the entropy weighted TOPSIS method [11]. Based on the proposed distance measure, Shen and $\mathrm{Ma}$ et al. developed an extended intuitionistic fuzzy TOPSIS approach to handle multicriteria decision-making problems [12]. Chen et al. adopt the improved TOPSIS method and sequence weighting to evaluate the level of transformation and upgrading of six resource-based cities in Shanxi province from 2001 to 2015 [13]. Mishra et al. propose a new integrated approach using analytical hierarchy process (AHP) and technique for order of preference by similarity to ideal solution (TOPSIS) methods for evaluation and prioritization of appropriate manufacturing flexibility type required in the context of multiple environmental uncertainties [14]. Existing research advances the optimization of TOPSIS evaluation method. The improvement of the TOPSIS evaluation method needs to be comprehensively analyzed. Some of them are indeed problems with the TOPSIS evaluation method itself, which of course needs to be enhanced. Others do not belong to the TOPSIS method itself, for example, increasing the evaluation objects. If the evaluation object contains a negative ideal solution, it will disarrange the entire order. This is very normal. Some scholars have proposed to optimize the setting of TOPSIS weights, but the weighting problem is the basic issue of multiattribute evaluation method and is not specific to the TOPSIS evaluation method. In general, TOPSIS is an excellent evaluation method, but it is meaningful to improve TOPSIS from the perspective of the evaluation index coordination. Currently, there are few related studies in this field, and it is necessary to take a deep dive into it.

First, evaluation of academic journals can be done from a variety of perspectives, including academic quality, journal influence, timeliness, and editorial quality. An excellent journal should strive to achieve comprehensive and coordinated development. Each evaluation index should not be lacking. However, for the current TOPSIS evaluation method, when certain indicators are low, they can be complemented when the other indicators are high.

Second, the coordinated development of academic journals is also in line with the laws of journal development. For example, the timely delivery of the robot journals is efficient, which is a manifestation of their academic quality. Editing and publishing excellence is also an integral part of journal quality. Journals with better academic quality are bound to have higher influence.

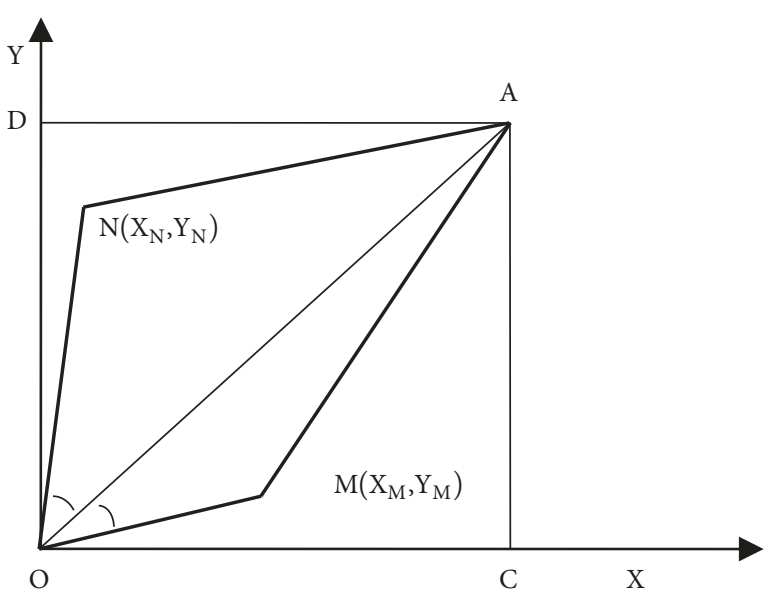

FIgURE 1: Coordination issues for evaluation.

Third, there are not many multiattribute methods which evaluate from the perspective of coordination. There are dozens of multiattribute evaluation methods. TOPSIS is only one of the evaluation methods. When TOPSIS is designed initially, the coordination of evaluation indicators is not considered. If improved, it can not only optimize the TOPSIS evaluation method and enrich the basic theory of evaluation but also have important practical significance for the evaluation of academic journals. It can also promote the all-round and balanced development of academic journals.

Based on the analysis of TOPSIS method principle, this paper proposes a coordinated TOPSIS evaluation method. Taking the JCR2016 Robotics Journal as an example, this paper studies the differences between the evaluation method and the original TOPSIS evaluation method and then summarizes the results.

\section{The Principles of Coordinated TOPSIS Evaluation Method}

2.1. Introduction to TOPSIS Evaluation Method. The traditional TOPSIS calculation formula is

$$
C_{i}=\frac{\sqrt{\sum_{j=1}^{n} \omega_{j}\left(x_{i j}-x_{j}^{-}\right)^{2}}}{\sqrt{\sum_{j=1}^{n} \omega_{j}\left(x_{i j}-x_{j}^{+}\right)^{2}}+\sqrt{\sum_{j=1}^{n} \omega_{j}\left(x_{i j}-x_{j}^{-}\right)^{2}}}
$$

In formula (1), $\mathrm{x}_{\mathrm{ij}}$ represents the standardized evaluation index, $x_{j}^{+}$is the positive ideal solution, its value is $\max (x \mathrm{j}) ; \mathrm{x}_{\mathrm{j}}^{-}$ is the negative ideal solution, its value is $\min \left(\mathrm{x}_{\mathrm{j}}\right)$, and $\mathrm{n}$ is the number of evaluation indicators. $C_{i}$ indicates the evaluation result of TOPSIS, and its value is between 0 and 1 , the larger the evaluation result, the better the evaluation object.

Figure 1 can further illustrate the TOPSIS evaluation principle. Assume that there are only two evaluation indicators $\mathrm{X}, \mathrm{Y}$, and $\mathrm{A}$ is normalized ideal solution with coordinates $(1,1)$. OA is $45^{\circ}$ straight line, also called the coordinated straight line. All points on OA line have the same value of the two evaluation indexes. The position of the negative ideal 


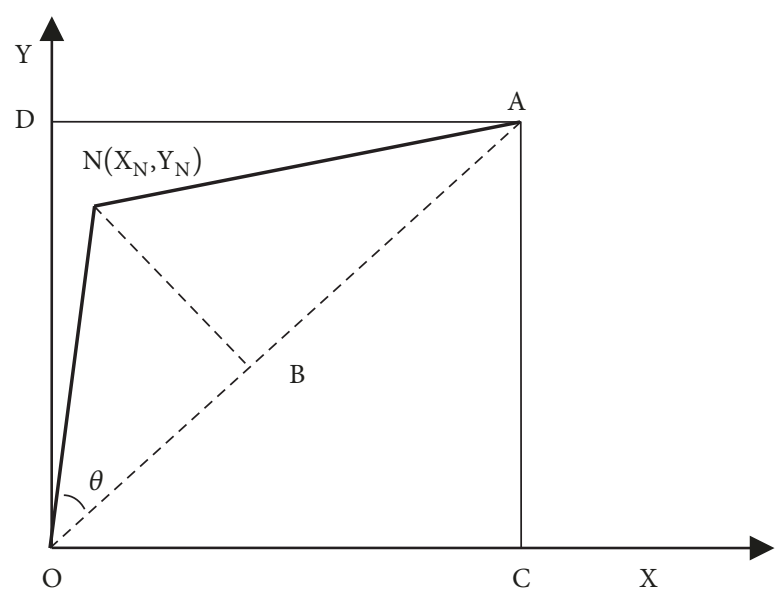

FIgURE 2: Calculation of coordination degree.

solution is uncertain. For simplicity, assume that the negative ideal solution is the origin and the coordinates are $(0,0)$. $\mathrm{M}$ is any point that needs to be evaluated and its coordinate value is $\left(X_{M}, Y_{M}\right)$. The distance from $M$ to the ideal solution is MA, and the distance to the negative ideal solution is OM. At this time, the TOPSIS evaluation value is

$$
C_{M}=\frac{O M}{O M+M A}
$$

2.2. Reflecting the Coordinated Development of Indicators. As shown in Figure 1, it is assumed that there are two evaluation objects $\mathrm{M}\left(\mathrm{X}_{\mathrm{M}}, \mathrm{Y}_{\mathrm{M}}\right)$ and $\mathrm{N}\left(\mathrm{X}_{\mathrm{N}}, \mathrm{Y}_{\mathrm{N}}\right)$, and for point $\mathrm{M}, \mathrm{X}_{\mathrm{M}}>$ $\mathrm{Y}_{\mathrm{M}}$; for point $\mathrm{N}, \mathrm{X}_{\mathrm{N}}<\mathrm{Y}_{\mathrm{N}}$. However, from the deviation degree of $\mathrm{X}, \mathrm{Y}$ evaluation index at points $\mathrm{M}$ and $\mathrm{N}, \mathrm{N}$ point deviates further from the OA line. This is because the abscissa $\mathrm{X}_{\mathrm{N}}$ of point $\mathrm{N}$ is much smaller than its ordinate $\mathrm{Y}_{\mathrm{N}}$, showing $\angle N O A>\angle A O M$. In other words, if the two indicators $\mathrm{X}, \mathrm{Y}$ are more coordinated, the gap between the values of the two should be smaller. In the case of limit, $\mathrm{X}=\mathrm{Y}$, that is located on the coordination line OA. The size of the coordination level can be represented by the angle of the line from the origin to the point and line OA. For point $M$, the angle is $\angle A O M$. For point $\mathrm{N}$, the angle is $\angle \mathrm{NOA}$. The smaller the angle is, the more coordinated it is.

2.3. The Degree of Coordination. As shown in Figure 2, in order to reflect the coordinated development of indicators in TOPSIS evaluation, which means the horizontal coordinate value should be close to its vertical coordinate value for any indicator, it is necessary to calculate the degree of coordination. The size of $\angle N O A$ indicates the level of coordination. The larger the angle is, the less coordinated it is. In other words, the bigger the indicator is, the less coordinated it is, just use $45^{\circ}-\angle \mathrm{NOA}$.

In order to find out the size of $\angle N O A$, you need to calculate the cosine of the angle first and then convert it by the inverse cosine function. Yu and Zhang proved that the length of $\mathrm{OB}$ is $\left(\mathrm{X}_{\mathrm{N}}+\mathrm{Y}_{\mathrm{N}}\right) / 2$, and the length of $\mathrm{ON}$ is the Euclidean distance from the point $\mathrm{N}$ to the origin, so that the cosine of the $\angle \mathrm{NOA}$ is solved [15].

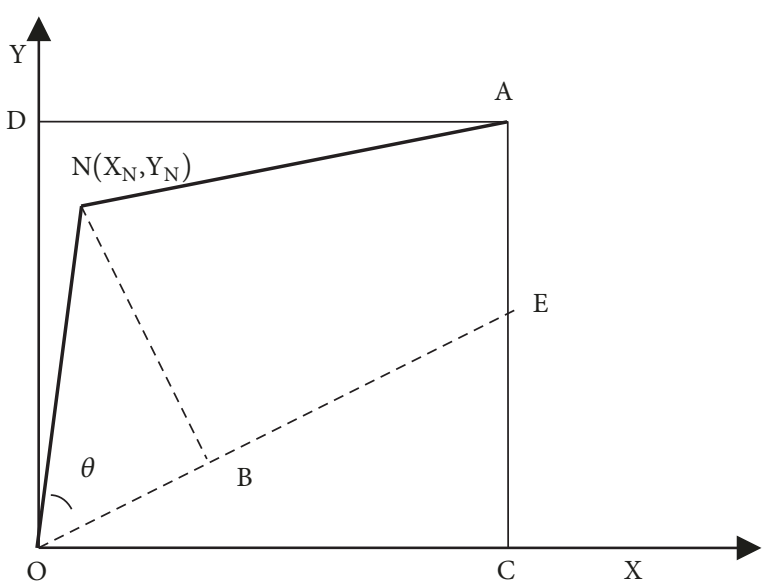

FIGURE 3: Weighted TOPSIS reference.

It can be utilized across the board. Assuming in general $\angle \mathrm{NOA}=\theta$, its cosine is

$$
\cos \left(\theta_{i}\right)=\frac{\sum_{j=1}^{n} x_{i j}}{n \sqrt{\sum_{j=1}^{n} x_{i j}^{2}}}
$$

The value of $\theta$ can be calculated using the inverse cosine function. The larger $\theta$ is, the more uncoordinated it is. The value of $\theta$ is $0^{-}-45^{\circ}$, if 45 is subtracted from $\theta$ and then divided by 45 , the degree of coordination can be obtained with a slight conversion. The maximum value is 1 and a minimum value is 0 :

$$
p_{i}=\frac{45-\theta_{i}}{45}
$$

This method can also be applied to weighted TOPSIS. There is no concept of weighting when the TOPSIS method was developed. Scholars such as Shyur, Deng et al., Yue and Zeng, and Xiao (2018) introduced weights to TOPSIS. The indicator coordination line of the weighted TOPSIS is not 45 straight line [16-19]. As shown in OE in Figure 3, because the weight of $\mathrm{X}$ is greater than that of $\mathrm{Y}$, resulting in the coordination reference line becoming $\mathrm{OE}$, closer to the $\mathrm{X}$-axis, the angle $\theta$ further increases and $\mathrm{N}$ is even more inconsistent. Angle $\theta$ may be greater than $45^{\circ}$. It may be less than 45 . However, it will certainly be less than 90 . Therefore, it is more reasonable to consider the use of 90 minus $\theta$ for the calculation of the degree of coordination after weighting.

In the weighted TOPSIS evaluation, the $\theta$ cosine size is

$$
\cos \left(\theta_{i}\right)=\frac{\sum_{j=1}^{n} \omega_{j} x_{i j}}{n \sqrt{\sum_{j=1}^{n} \omega_{j} x_{i j}^{2}}}
$$

Due to the weighted TOPSIS, the reference baseline is not 45. Therefore, when calculating the degree of coordination, it is better to convert using 90 , that is,

$$
p_{i}=\frac{90-\theta_{i}}{90}
$$


2.4. Coordinated TOPSIS Method. To revise TOPSIS from the point of view of coordinated development, two issues must be considered. First, the TOPSIS evaluation results must be considered to reflect the superiority and characteristics of TOPSIS, and the second is coordination. As for the synthesis of the two, there are two ideas, one is to take additive synthesis, and the other is multiplication synthesis. For the multiplication synthesis, for points on X-axis or Yaxis, which are completely uncoordinated, the coordination degree is 0 , so the overall evaluation value is 0 , which is not in line with the usual; therefore additive synthesis is adopted. The weight of the coordination degree can also be set according to the purpose of the evaluation. For this purpose, the coordination weight $\mathrm{v}$ is introduced, $0<\mathrm{v}<1$. If the assessment is to encourage the coordinated development of the evaluation indicators, $\mathrm{v}$ must be greater than or equal to 0.5 .

In addition, we must pay attention to the dimensional issue of the TOPSIS evaluation value and coordination degree. In TOPSIS evaluation, since the positive and negative ideal solutions are often not in the same evaluation object, the theoretical maximum value is 1 and the minimum value is 0 . However, this situation often does not exist in actual evaluation. In order to combine TOPSIS evaluation values and coordination degree, the TOPSIS evaluation results must be standardized. In the same way, the degree of coordination also needs to be standardized. This coordination formula is

$$
T_{i}=(1-v) \frac{C_{i}}{\max \left(C_{i}\right)}+v \frac{p_{i}}{\max \left(p_{i}\right)}
$$

In this equation, $\mathrm{C}_{\mathrm{i}}$ is the evaluation results; $\mathrm{P}_{\mathrm{i}}$ is coordination degree; $v$ is the weight of adjustment. The coordination degree is an important adjustment indicator in that coordinated development of various types of indicators needs to be encouraged. The differences between these indicators should not be too big.

2.5. Explanation of Coordinated TOPSIS Evaluation Using Absolute Negative Ideal Solution. In TOPSIS evaluation, if a negative ideal solution is used, the line between negative ideal solution to the ideal solution will not normally be $45^{\circ}$. It is not meaningful to use the non- $45^{\circ}$ line as a criterion to judge whether or not the evaluation indicators are coordinated. This is because the coordination reference standard is not unique. In this circumstance, a more scientific approach is to adopt an absolute negative ideal solution, that is, to use the origin as a negative ideal solution. In addition, the use of an absolute negative ideal solution can also fundamentally eliminate disorder problem in TOPSIS. The sequences of all evaluation results will be changed if the negative ideal solution changes.

It should be noted that, in the following empirical research, in order to conduct a comparative analysis of TOPSIS and coordinated TOPSIS, absolute negative ideal solutions are used in TOPSIS evaluation, and the value at the origin of the coordinate axis is the worst value.

\section{Sources of Data}

This article takes the JCR2016 Robotics Journal as an example to compare and analyze TOPSIS and coordinated TOPSIS evaluation results. The robotics discipline is one of the few disciplines in JCR 2016, with a total of 26. Since the four journals "IEEE Transactions on Cognitive and Developmental Systems," "Intelligent Service Robotics," "IEEE Transactions on Autonomous Mental Development," and "Frontiers in Neurorobotics" have missing data, they are not considered, so there are actually only 22 journals.

JCR2016 published a total of 11 indicators, namely, Total Cites, Journal Impact Factor, Impact Factor without Journal Self Cites, 5-Year Impact Factor, Immediacy Index, Cited Half-Life, Citing Half-life, Eigenfactor Score, and Article Influence Score. Average Journal Impact Factor Percentile, Normalized Eigenfactor, and Since Normalized Eigenfactor is derived linearly from characteristic factors, it is removed to avoid data duplication, Average Journal Impact Factor Percentile is calculated based on the impact factor, and it belongs to the ranking index, which is discontinuous numerical index. Therefore, it is also deleted. Nine indicators are used for evaluation, and the statistics of the data are shown in Table 1.

All indicators must be standardized during the evaluation. The normalization method of the forward indicator is to divide the original indicator value by its maximum value. The cited half-life and the citing half-life are two reverse indexes that need to be processed in a forward direction. The standardized formula is as follows:

$$
x_{i j}=\frac{x_{i j}^{\prime}-\max \left(x_{j}^{\prime}\right)}{\max \left(x_{j}^{\prime}\right)-\min \left(x_{j}^{\prime}\right)}
$$

In formula (8), $\mathrm{x}_{\mathrm{i}}$ is the standardized evaluation index, $\mathrm{x}_{\mathrm{ij}}^{\prime}$ is the original index data, $\max ()$ is the maximum value, and $\min ()$ is the minimum value.

\section{Evaluation Results Comparison}

First of all, the TOPSIS method is used for evaluation. For the sake of simplicity, the weights of the nine evaluation indexes are set equal to 0.111 . Next, the coordinated TOPSIS is used to evaluate. The weight of the coordination degree is set to 0.5 , and the weight of the TOPSIS evaluation is also 0.5 . The evaluation results are shown in Table 2.

From the average of all the journals, the overall $\theta$ is high, the average tilt is 73.529 degree, and the gap between the journals is not large, indicating that the coordination of the journal is not good. The root cause is the large data distribution of bibliometric indicators in academic journals. Seglen finds that the citation data exhibited a typical skewed distribution. Outliers caused large variations in the statistical mean [20]. Vinkler also finds the right bias of the citation distribution [21].

From the ranking of evaluation results, after considering the coordination degree, the ranking of the evaluation results of the coordinated TOPSIS differs greatly from that of the TOPSIS. There are only four types of journals that are 
TABLE 1: Index description statistics.

\begin{tabular}{|c|c|c|c|c|c|}
\hline Evaluation index & Mean & Median & Maximum & Minimum & Std. Dev. \\
\hline Total Cites & 2301.000 & 1501.000 & 12478.000 & 144.000 & 2920.082 \\
\hline Journal Impact Factor & 2.540 & 2.380 & 8.649 & 0.500 & 1.915 \\
\hline Impact Factor without Journal Self Cites & 2.249 & 1.902 & 7.108 & 0.390 & 1.703 \\
\hline 5-Year Impact Factor & 2.950 & 2.440 & 9.243 & 0.406 & 2.236 \\
\hline Immediacy Index & 0.430 & 0.426 & 1.390 & 0.053 & 0.336 \\
\hline Cited Half-Life & 6.241 & 6.550 & 10.000 & 2.300 & 1.867 \\
\hline Citing Half-life & 7.991 & 8.000 & 10.000 & 4.900 & 1.041 \\
\hline Eigenfactor Score & 0.003 & 0.002 & 0.013 & 0.000 & 0.003 \\
\hline Article Influence Score & 0.752 & 0.481 & 2.792 & 0.091 & 0.682 \\
\hline
\end{tabular}

TABLE 2: Comparison of TOPSIS and coordinated TOPSIS evaluation.

\begin{tabular}{|c|c|c|c|c|c|c|}
\hline JCR Abbreviated Title & $\begin{array}{c}\text { Angle } \\
\Theta\end{array}$ & $\begin{array}{c}\text { Coordination } \\
\text { Degree } \mathrm{P}_{\mathrm{i}}\end{array}$ & $\begin{array}{c}\text { TOPSIS } \\
\text { Value } \\
\mathrm{C}_{\mathrm{i}}\end{array}$ & $\begin{array}{l}\text { TOPSIS } \\
\text { Ranking }\end{array}$ & $\begin{array}{c}\text { Coordinated } \\
\text { TOPSIS } \\
\text { Value } \\
\mathrm{T}_{\mathrm{i}}\end{array}$ & Ranking \\
\hline INT J ROBOT RES & 71.479 & 0.206 & 0.610 & 2 & 0.967 & 1 \\
\hline SOFT ROBOT & 72.970 & 0.189 & 0.633 & 1 & 0.947 & 2 \\
\hline IEEE ROBOT AUTOM MAG & 72.314 & 0.197 & 0.507 & 4 & 0.864 & 3 \\
\hline IEEE T ROBOT & 73.132 & 0.187 & 0.515 & 3 & 0.849 & 4 \\
\hline J FIELD ROBOT & 71.539 & 0.205 & 0.426 & 5 & 0.821 & 5 \\
\hline BIOINSPIR BIOMIM & 71.751 & 0.203 & 0.415 & 6 & 0.806 & 6 \\
\hline ROBOT CIM-INT MANUF & 72.060 & 0.199 & 0.401 & 7 & 0.787 & 7 \\
\hline AUTON ROBOT & 70.934 & 0.212 & 0.346 & 8 & 0.773 & 8 \\
\hline ROBOT AUTON SYST & 71.140 & 0.210 & 0.302 & 13 & 0.733 & 9 \\
\hline SWARM INTELL-US & 72.320 & 0.196 & 0.322 & 12 & 0.718 & 10 \\
\hline J BIONIC ENG & 73.465 & 0.184 & 0.333 & 9 & 0.696 & 11 \\
\hline J MECH ROBOT & 73.416 & 0.184 & 0.328 & 11 & 0.694 & 12 \\
\hline INT J SOC ROBOT & 73.853 & 0.179 & 0.329 & 10 & 0.683 & 13 \\
\hline J INTELL ROBOT SYST & 73.478 & 0.184 & 0.278 & 15 & 0.652 & 14 \\
\hline ROBOTICA & 72.311 & 0.197 & 0.167 & 20 & 0.596 & 15 \\
\hline INT J ADV ROBOT SYST & 76.305 & 0.152 & 0.296 & 14 & 0.593 & 16 \\
\hline ADV ROBOTICS & 73.395 & 0.185 & 0.193 & 18 & 0.588 & 17 \\
\hline INT J HUM ROBOT & 73.707 & 0.181 & 0.162 & 21 & 0.555 & 18 \\
\hline IND ROBOT & 74.480 & 0.172 & 0.171 & 19 & 0.542 & 19 \\
\hline APPL BIONICS BIOMECH & 75.557 & 0.160 & 0.159 & 22 & 0.504 & 20 \\
\hline INT J ROBOT AUTOM & 77.649 & 0.137 & 0.203 & 16 & 0.484 & 21 \\
\hline REV IBEROAM AUTOM IN & 80.377 & 0.107 & 0.195 & 17 & 0.407 & 22 \\
\hline Average & 73.529 & 0.183 & 0.331 & - & 0.694 & -- \\
\hline
\end{tabular}

completely consistent in the ranking of the two evaluation methods, accounting for $18.18 \%$ of all journals. Because the overall number of robotics journals is small, this situation will be more serious for other disciplines that have more journals.

The degree of correlation between TOPSIS and coordinated TOPSIS evaluation results is relatively high. The correlation coefficient is 0.939 , indicating a high degree of consistency between the two. From the scatter plot of the evaluation results (Figure 4), when the score is higher, the two have more similar results, and vice versa.

\section{Conclusions and Discussion}

Coordinated TOPSIS is an evaluation method that takes into account the coordination of evaluation indicators and the advantages of TOPSIS evaluation. In accordance with TOPSIS evaluation, this paper proposes a method to determine the degree of coordination. The principle is to measure the angle between the line from the evaluation object to the origin and the ideal solution to the origin. The smaller the angle is, the better the coordination of the indicators is. Based on this result, a new evaluation method, coordinated TOPSIS, 


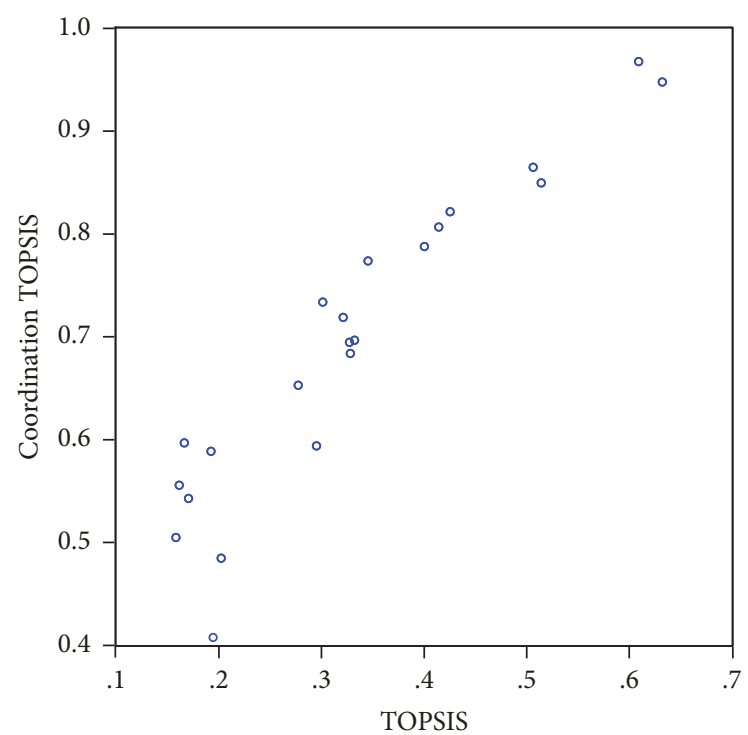

FIGURE 4: Comparison of scatter plots of evaluation results.

is proposed, combining TOPSIS and coordination level. The weight of the coordination degree can be manually adjusted according to the purpose of evaluation, and it can be widely applied when the coordination level of indicators need to be taken into account

The empirical research shows that the TOPSIS evaluation results have a high correlation with the coordinated TOPSIS evaluation results, but they differ significantly from the ranking perspective. Because there are few robot academic journals in this study, this sort of difference has been shown. The ranking difference will be even greater for subjects with more academic journals. The evaluation method cannot be simply chosen for a higher correlation coefficient. It should be based on the purpose of the evaluation and the principle of the evaluation method. After all, the choice of evaluation methods will have a significant impact on the results.

Coordinated TOPSIS is very suitable for evaluation field that needs to consider the coordinated development, and it can be replicated. In the evaluation of science and technology, the balanced development of evaluation indicators has become more and more important, such as academic quality and influence, technology and economy, scientific $\mathrm{R} \& \mathrm{D}$, and transformation of achievements, etc. As far as the field of economic and social development is concerned, more areas need to consider coordinated development. Therefore, coordinated TOPSIS has a wide range of applications, which can be selected according to the purpose of evaluation and extended to some extent.

\section{Data Availability}

The data used to support the findings of this study are included within the article.

\section{Conflicts of Interest}

The authors declare that they have no conflicts of interest.

\section{Acknowledgments}

This paper is supported by the Major Project of National Social Science Fund of China (No. 16ZDA053), Humanities and Social Sciences Projects of the Ministry of Education (17YJA630125), Philosophy and Social Science Foundation of Zhejiang Province (17NDJC107YB), and China's National Natural Science Foundation Project (71663058). The authors thank them heartedly for supporting the paper funds.

\section{References}

[1] C. L. Hwang and K. Yoon, "Methods for multiple attribute decision making," in Multiple Attribute Decision Making, vol. 186 of Lecture Notes in Economics and Mathematical Systems, pp. 58-191, Springer, Heidelberg, Germany, 1981.

[2] J. Xu, Z. Li, W. Shen, and B. Lev, "Multi-attribute comprehensive evaluation of individual research output based on published research papers," Knowledge-Based Systems, vol. 43, pp. 135-142, 2013.

[3] L. Yu, X. Shen, Y. Pan, and Y. Wu, "Scholarly journal evaluation based on panel data analysis," Journal of Informetrics, vol. 3, no. 4, pp. 312-320, 2009.

[4] Z. Li, M. Liechty, J. Xu, and B. Lev, "A fuzzy multi-criteria group decision making method for individual research output evaluation with maximum consensus," Knowledge-Based Systems, vol. 56, pp. 253-263, 2014.

[5] L. P. Yu, Y. T. Pan, and Y. S. Wu, "Application of TOPSIS in journal evaluation and its promotion under high power," Journal of Statistical Research, vol. 29, no. 12, pp. 96-101, 2012.

[6] G. R. Jahanshahloo, F. H. Lotfi, and M. Izadikhah, "Extension of the TOPSIS method for decision-making problems with fuzzy data," Applied Mathematics and Computation, vol. 181, no. 2, pp. 1544-1551, 2006.

[7] L. P. Yu, Y. T. Pan, and Y. S. Wu, "Revised TOPSIS and its application research in science and technology evaluation," Intelligence Magazine, vol. 31, no. 6, pp. 103-107, 2012.

[8] Y. K. Li and J. R. Zhang, "The reverse order problem," Science and Technology Journal, vol. 26, no. 7, pp. 47-50, 2008.

[9] W. F. Lu and H. X. Tang, "A comprehensive improvement of TOPSIS method for multi-attribute decision making," Statistics and Decision, no. 19, pp. 38-40, 2012.

[10] C. B. Li, J. Y. Zhang, Y. D. Gu, and Z. Q. Qi, "A fuzzy stochastic multi-criteria decision making method and application based on prospect theory and improved TOPSIS," Operations Research and Management, vol. 24, no. 2, pp. 92-100, 2015.

[11] L.-Y. Sun, C.-L. Miao, and L. Yang, "Ecological-economic efficiency evaluation of green technology innovation in strategic emerging industries based on entropy weighted TOPSIS method," Ecological Indicators, vol. 73, pp. 554-558, 2017.

[12] F. Shen, X. Ma, Z. Li, Z. Xu, and D. Cai, "An extended intuitionistic fuzZy TOPSIS method based on a new distance measure with an application to credit risk evaluation," Information Sciences, vol. 428, pp. 105-119, 2018.

[13] W. Chen, Y. Shen, and Y. Wang, "Evaluation of economic transformation and upgrading of resource-based cities in Shaanxi 
province based on an improved TOPSIS method," Sustainable Cities and Society, vol. 37, pp. 232-240, 2018.

[14] R. Mishra, A. K. Pundir, and L. Ganapathy, "Evaluation and prioritisation of manufacturing flexibility alternatives using integrated AHP and TOPSIS method: Evidence from a fashion apparel firm," Benchmarking, vol. 24, no. 5, pp. 1437-1465, 2017.

[15] L. P. Yu and Q. Zhang, "A study of the nature of two types of utility function evaluation methods in journal evaluation," Journal of Intelligence, no. 10, pp. 1077-1082, 2014.

[16] H. J. Shyur, "COTS evaluation using modified TOPSIS and ANP," Applied Mathematics and Computation, vol. 177, no. 1, pp. 251-259, 2006.

[17] H. Deng, C.-H. Yeh, and R. J. Willis, "Inter-company comparison using modified TOPSIS with objective weights," Computers \& Operations Research, vol. 27, no. 10, pp. 963-973, 2000.

[18] Z. Yue, "An extended TOPSIS for determining weights of decision makers with interval numbers," Knowledge-Based Systems, vol. 24, no. 1, pp. 146-153, 2011.

[19] S. Zeng and Y. Xiao, "A method based on topsis and distance measures for hesitant fuzzy multiple attribute decision making," Technological and Economic Development of Economy, vol. 24, no. 3, pp. 969-983, 2018.

[20] P. O. Seglen, “The skewness of science," Journal of the Association for Information Science and Technology, vol. 43, no. 9, pp. 628638, 1992.

[21] P. Vinkler, "Introducing the Current Contribution Index for characterizing the recent, relevant impact of journals," Scientometrics, vol. 79, no. 2, pp. 409-420, 2009. 


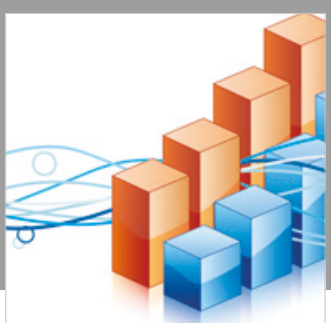

Advances in

Operations Research

\section{-n-m}
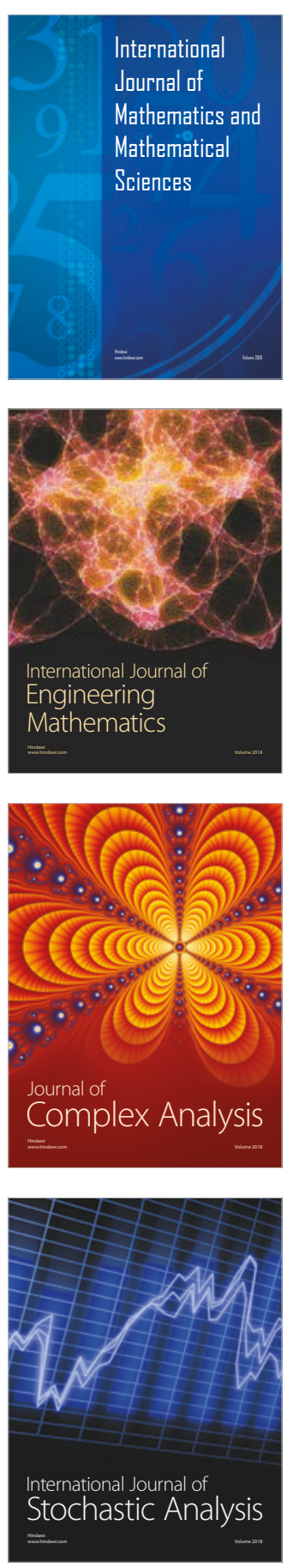
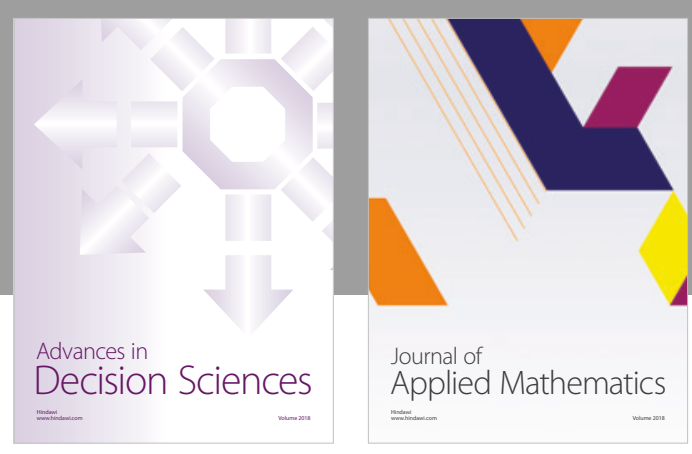

Journal of

Applied Mathematics
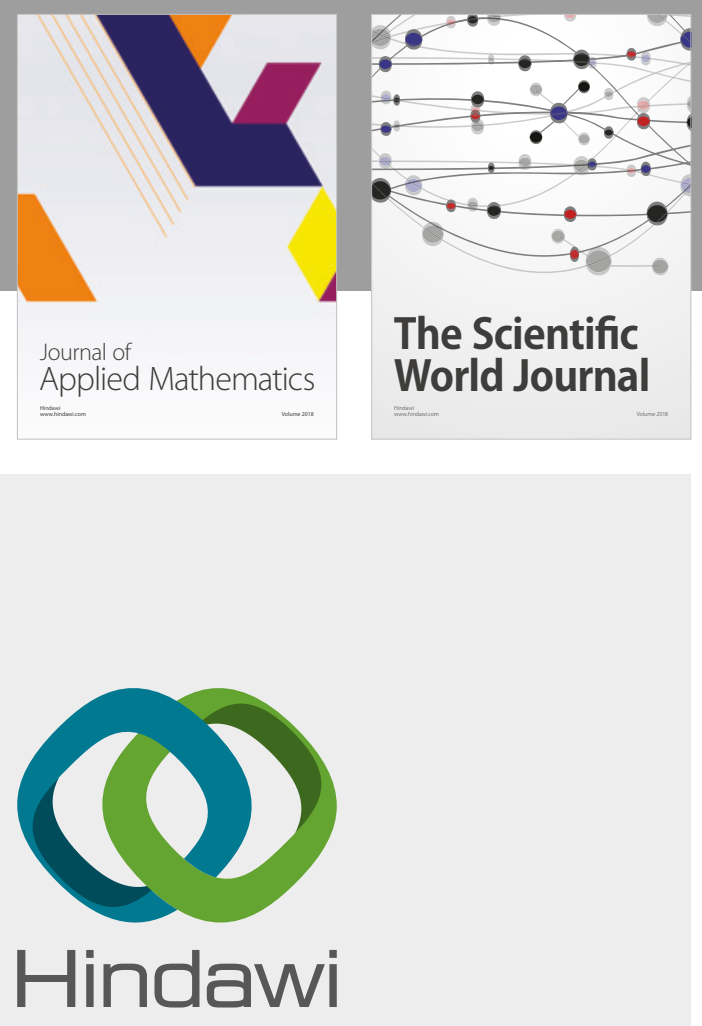

Submit your manuscripts at

www.hindawi.com

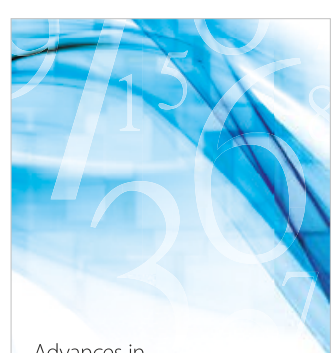

Advances in
Numerical Analysis
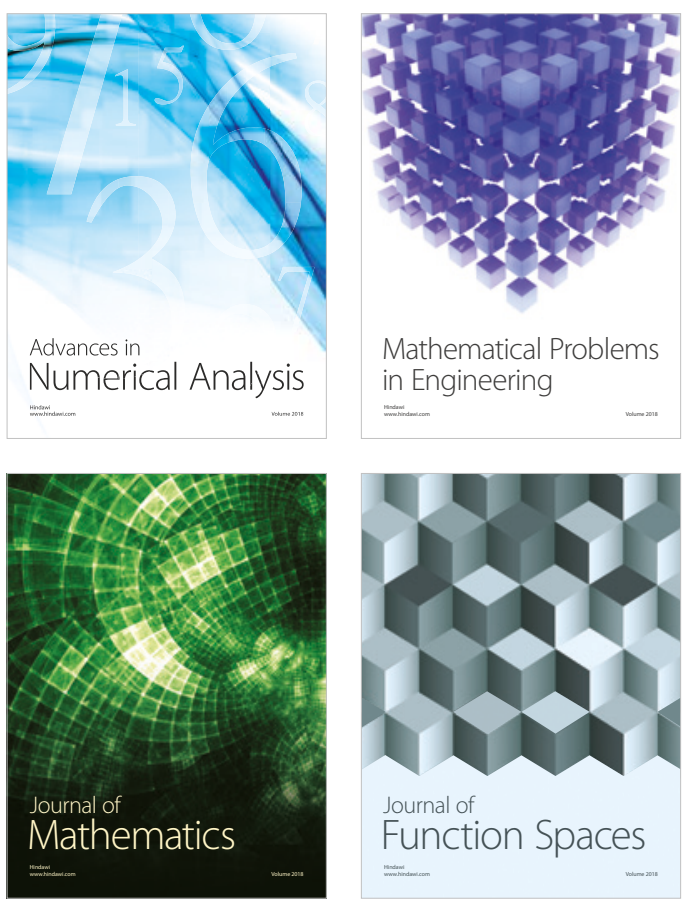

Mathematical Problems in Engineering

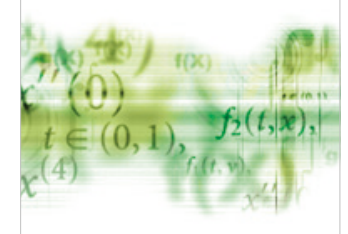

International Journal of

Differential Equations

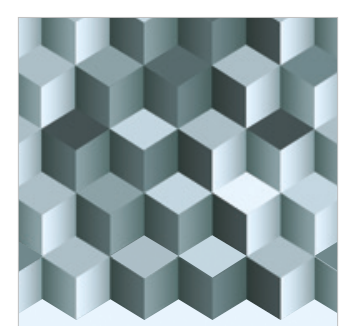

Journal of

Function Spaces

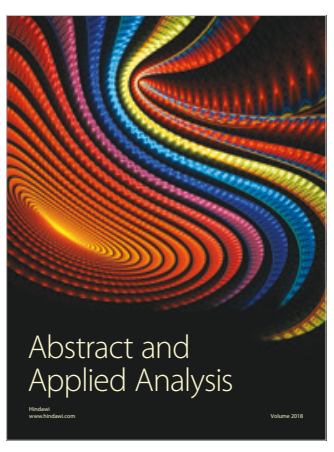

The Scientific

World Journal

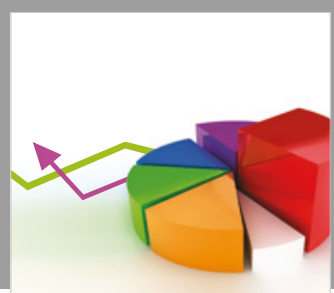

Journal of

Probability and Statistics
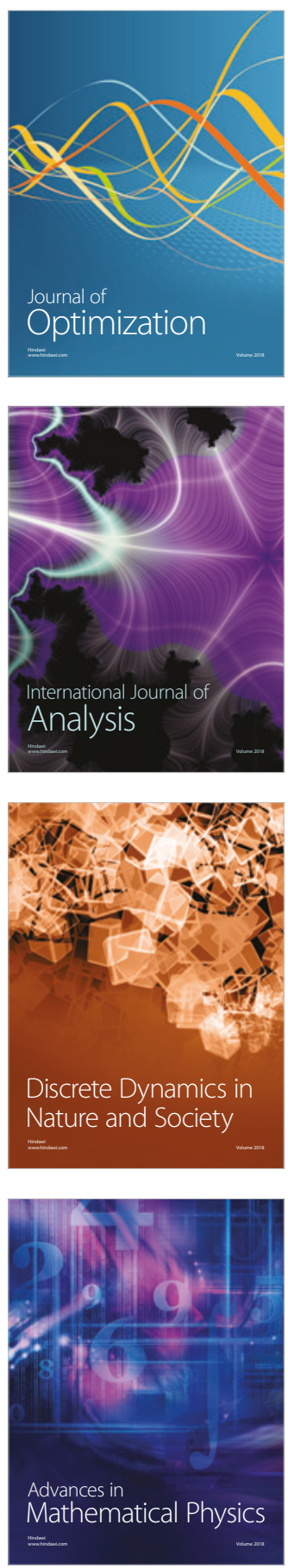